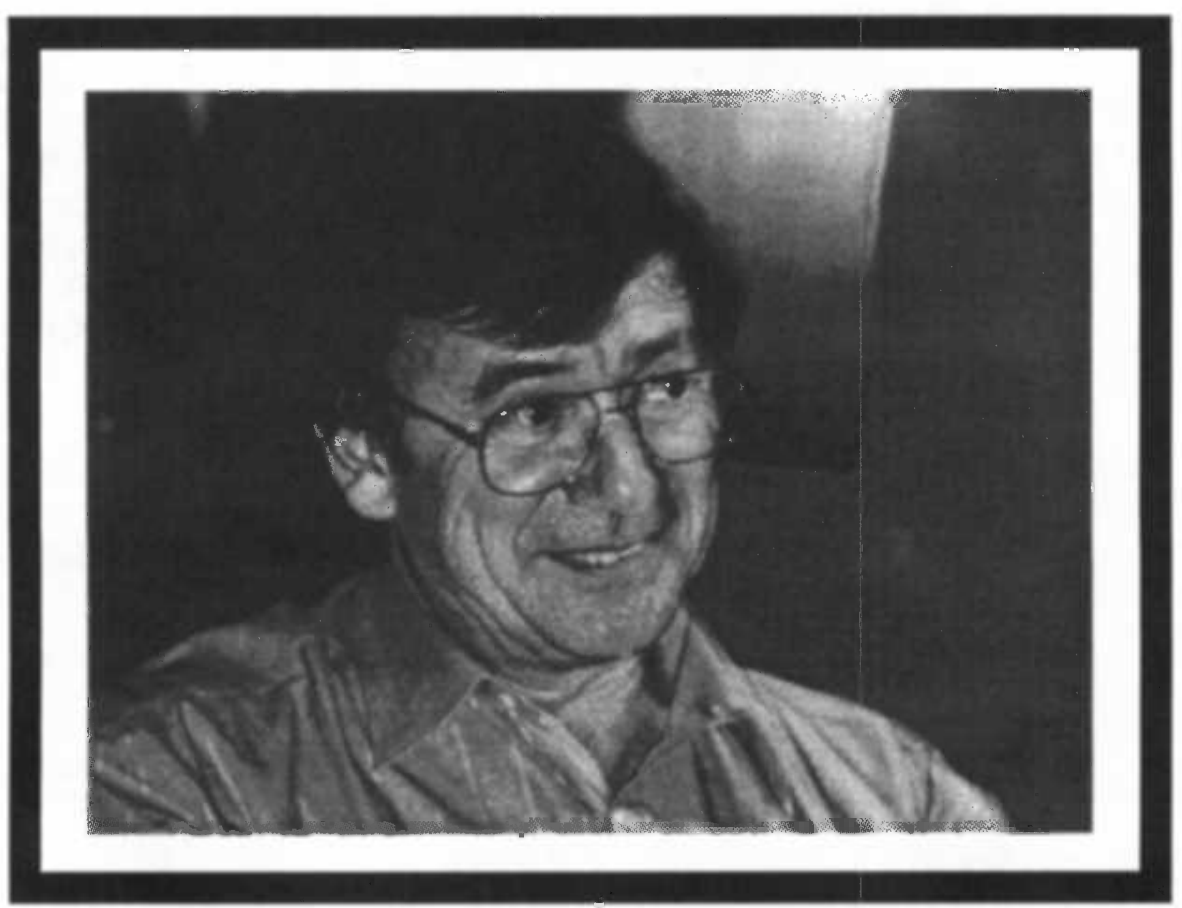

Jean-Charles Fontes, photograph taken in Tucson, Arizona, May 1991

\title{
JEAN-CHARLES FONTES (3 NOVEMBER 1936 - 2 FEBRUARY 1994)
}

The untimely death of Jean-Charles Fontes on 2 February 1994 came as a shock to all who knew him. We lost a friend, colleague and an extremely good scientist in a car accident in Mali, a country he loved like many other countries and places in Africa.

Jean-Charles lived for his science and had reached the point in his career where he wanted to use his knowledge and friendships throughout the world to strengthen the international involvement of the Atomic Energy Agency in Vienna in global research and monitoring programs in the fields of isotope hydrology, geochemistry and climatology. He accepted this challenge as Head of the Section of Isotope Hydrology just a few months ago; he was already deeply involved in planning strategies for the future. We all looked forward to these developments.

The 284 publications $^{1}$ that Jean-Charles wrote reflect his vast scientific knowledge and experience and his critical mind. Whoever had the privilege to have a manuscript reviewed by him will miss his analyses and questions.

The foundation for his scientific knowledge was laid at the Ecole Normale Supérieure de St. Cloud. His stay during the early 1960s at the Laboratorio di Geologia Nucleare in Pisa represented a turning point in his scientific development. This laboratory was one of the most important centers for isotope geology in Europe and was host to many isotope geochemists active at that time. Those who had the opportunity to be there were formed for life. Jean-Charles was an important element in this group, and friendships formed then were never lost.

'Editors' note: A selected bibliography is not given here because plans are being made to publish a special memorial volume. 
He moved back to the University of Paris and then to the University of Paris-Sud (Orsay) where he became Full Professor, Director of the Laboratoire d'Hydrologie et de Géochimie Isotopique and member of numerous national and international committees. His research became truly international with a strong focus on the problems of Africa and a deep involvement in the activities of the IAEA in Vienna. As a frequent expert on missions for the IAEA and other UN organizations and within the framework of international collaboration, he visited and worked on all continents of this globe. At Orsay, he pursued with vigor the development of accelerator-based mass spectrometry. His contributions to the measurement and interpretation of ${ }^{14} \mathrm{C}$ and ${ }^{36} \mathrm{Cl}$ will be, for a long time, standard references.

Those who can read his papers in the original French will find that his love of the French language, which he used with great mastery and elegance, permeates his writings in which he covered topics in theoretical isotope geochemistry, sedimentology, paleoclimatology and isotope hydrology. JeanCharles' work was thorough science and good literature.

We will miss his friendship, contributions to science and intense discussions.

Peter Fritz, Roberto Gonfiantini and GianMaria Zuppi 